Brit. J. Ophthal. (1957) 41, 440.

\title{
COMPLETE RETROFLEXION OF THE IRIS WITH RETENTION OF NORMAL VISION*
}

BY

\author{
A. J. OGG \\ Salisbury
}

Case Report

A male aged 20 years was involved in a motor-bicycle collision in April, 1956. He was admitted on the same day to hospital in a confused state; he was unable to give a clear history, nor subsequently could he remember anything of the accident.

Examination.-The lids of the right eye were bruised, and the conjunctiva was considerably injected. In the lower third of the cornea was a small stellate rupture. The anterior chamber was present but shallow, and contained a $3 \mathrm{~mm}$. hyphaema. No iris structure was visible. After 2 days, during which time both eyes were padded, the anterior chamber had reformed and the hyphaema had almost cleared; 18 days after the accident the patient's general condition was sufficiently good for a slit-lamp examination. The rupture of the cornea had soundly healed. The iris was found to be completely retroflexed and could be seen rolled back and firmly attached to the ciliary processes; the entire zonule was visible and was found to be undamaged. The lens was in no way injured or displaced. The angle of the anterior chamber was normal. No abnormality was found in the fundus, and the uncorrected visual acuity was $6 / 12$.

Follow-up.-When last seen, nearly 9 months after the accident, the uncorrected visual acuity in the injured eye was $6 / 6$, and the patient was able to read J.1 with ease. There was no evidence of intra-ocular activity or raised tension, and the lens remained completely clear. The patient's only symptom was one of slight photophobia in bright light.

At no time did the injured eye receive treatment with a mydriatic or miotic.

The Figure shows an enlarged slit-lamp photograph of a portion of the lens equator and the edge of the retroflexed iris.

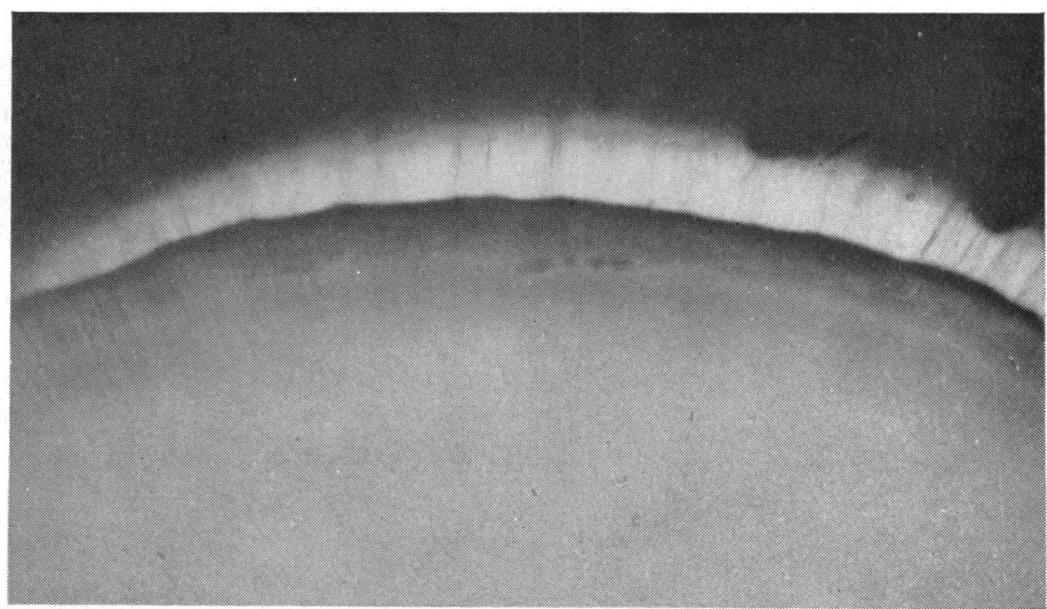

FIGURE.--Right eye, showing edge of retroflexed iris, two ciliary processes, and equator of the lens. Some equatorial and anterior zonular fibres are also shown.

* Received for publication February 20, 1957. 


\section{Discussion}

Complete retroflexion of the iris is of rare occurrence. Parsons (1908), in a review of the recorded cases, found partial or complete rupture of the zonule an almost universal event, and the lens was usually dislocated. DukeElder (1954) described traumatic cataract and violent iridocyclitis as frequent accompaniments.

The interesting features of this case are that, despite a rupture of the cornea and complete iris retroflexion, the youthful zonule and lens are undamaged and the eye sees $6 / 6$.

\section{REFERENCES}

Duke-Elder, S. (1954). " “Text-book of Ophthalmology”, vol. 6, p. 5793. Kimpton, London. PARSONS, J. H. (1908). "The Pathology of the Eye", vol. 4, p. 1144 . Hodder and Stoughton, London. 